\title{
A Novel Bacterium-Like Particle Vaccine Displaying the MERS-CoV Receptor-Binding Domain Induces Specific Mucosal and Systemic Immune Responses in Mice
}

\author{
Entao Li ${ }^{1,2}$, Hang Chi ${ }^{2,3}, *$, Pei Huang ${ }^{2,4}$, Feihu Yan ${ }^{2}$, Ying Zhang ${ }^{2,5}$, Chuanyu Liu ${ }^{2,4}$, \\ Zhenshan Wang ${ }^{2,4}$, Guohua Li ${ }^{2,6}$, Shengnan Zhang ${ }^{2,5}$, Ruo Mo ${ }^{2,4}$, Hongli Jin 2,7, \\ Hualei Wang ${ }^{2,7}$, Na Feng ${ }^{2,3}$, Jianzhong Wang ${ }^{4}$, Yuhai Bi ${ }^{8}$, Tiecheng Wang ${ }^{2,3}$, Weiyang Sun ${ }^{2,3}$, \\ Yuwei Gao ${ }^{2,3}$, Yongkun Zhao ${ }^{2,3, *}$, Songtao Yang ${ }^{2,3, *(1)}$ and Xianzhu Xia ${ }^{2,3, *}$ \\ 1 College of Veterinary Medicine, South China Agricultural University, Guangzhou 510642, China \\ 2 Changchun Veterinary Research Institute, Chinese Academy of Agricultural Sciences, \\ Changchun 130000, China \\ 3 Key Laboratory of Jilin Province for Zoonosis Prevention and Control, Changchun 130000, China \\ 4 Animal Science and Technology College, Jilin Agricultural University, Changchun 130118, China \\ 5 College of Wildlife and Protected Area, Northeast Forestry University, Harbin 150040, China \\ 6 College of Animal Science and Technology, Shihezi University, Shihezi 832003, China \\ 7 College of Veterinary Medicine, Jilin University, Changchun 130062, China \\ 8 CAS Key Laboratory of Pathogenic Microbiology and Immunology, Institute of Microbiology, \\ Chinese Academy of Sciences, Beijing 100101, China \\ * Correspondence: ch_amms@163.com (H.C.); zhaoyongkun1976@126.com (Y.Z.); yst62041@163.com (S.Y.); \\ xiaxzh@cae.cn (X.X.)
}

Received: 19 July 2019; Accepted: 27 August 2019; Published: 29 August 2019

check for updates

\begin{abstract}
Middle East respiratory syndrome coronavirus (MERS-CoV), a new coronavirus that has been causing severe and fatal acute respiratory illnesses in humans since its outbreak in 2012, has raised public fear worldwide. The development of prophylactics and therapeutics is urgently needed to prevent and control MERS-CoV infections. In this study, a bacterium (Lactococcus lactis)-like particle (BLP) vaccine displaying the MERS-CoV receptor-binding domain (RBD) was developed, and gram-positive enhancer matrix (GEM) particles were used as substrates to externally bind to the MERS-CoV RBD through a protein anchor (PA). The designs included different numbers of lysin motif (LysM) repeats in the PAs linked by linkers (RBD-linker-PA2 $\left(\mathrm{RLP}_{2}\right), \mathrm{RBD}-$ linker-PA3 $\left(\mathrm{RLP}_{3}\right)$ and RBD-PA3 $\left.\left(\mathrm{RP}_{3}\right)\right)$, and three LysM repeats and a linker in the fusion proteins increased the binding activity to the RBD. The specific immune responses were tested by intranasally immunizing mice with $\mathrm{RLP}_{3}$-GEM with or without the adjuvant GEL01. The results showed that GEL01-adjuvanted $\mathrm{RLP}_{3}$-GEM increased the systemic humoral, cellular and local mucosal immune responses in the mouse model, especially in the intestinal tract. The above results indicate that the MERS-CoV BLP product has the potential to be developed into a promising mucosal candidate vaccine to protect against MERS-CoV infections.
\end{abstract}

Keywords: MERS-CoV; subunit vaccine; bacterium-like particles; intranasal administration; mucosal immune

\section{Introduction}

Middle East respiratory syndrome coronavirus (MERS-CoV), a beta coronavirus, causes severe and lethal acute respiratory disease in humans and is remarkably different from other human coronaviruses, 
including HCoV-229E, HCoVNL63, HCoV-HKU1, and HCoV-OC43, which are known to cause mild respiratory infections [1,2]. Until May 2019, the World Health Organization (WHO) had received 2428 laboratory-confirmed cases from 27 countries after MERS-CoV was identified in 2012; these cases included 838 deaths related to MERS-CoV infections and had a case fatality rate of $35 \%$ [3]. In May 2015 the MERS outbreak in South Korea, which was the largest outbreak outside the Middle East and caused 36 deaths in 186 cases from a single infected person [4,5]; this outbreak raised the concerns of a potential global MERS-CoV pandemic. However, there are currently no licensed therapeutic drugs or prophylactic vaccines available to protect against MERS-CoV. Vaccination is the best way to control and prevent infectious diseases [6]. Since MERS-CoV is a respiratory pathogen, any MERS-CoV vaccination that induces antigen-specific secretory $\operatorname{IgA}(\mathrm{sIg} \mathrm{A})$ antibodies at the mucosal surfaces probably has the effects of preventing MERS-CoV replication at the site of virus infection [7]. The mode of MERS-CoV transmission is not clearly understood, but one study has proven that the human intestinal tract may be a new transmission route for MERS-CoV [8], indicating that antigen-specific sIgA antibodies in the gastrointestinal mucosa are a considerable indicator. Therefore, there is an urgent need to develop an effective mucosal immune vaccine against MERS-CoV, especially those inducing gastrointestinal mucosal immunity.

Up to date, researchers have developed a number of promising approaches for MERS-CoV vaccine candidates, including DNA vaccines [9-11], recombinant viral vectors [12-18], and protein-based platforms [6,19]. However, no vaccines have entered clinical trials except for a DNA vaccine that completed phase I clinical trials [20]. Each of these different MERS-CoV vaccine approaches has its own advantages and disadvantages, such as immunogenicity, ease of mass production, and preexisting immunity in addition to having potential adverse effects. These factors must be taken into account and balanced to create a successful vaccine for use in humans and/or animals. Subunit vaccines, consisting of the major pathogen antigenic fragments, possess many advantages, such as minimal side effects, high safety profiles, and a high yield [21,22]. Until now, some studies have shown that the receptor-binding domain (RBD) of the MERS-CoV spike (S) protein was a major antigenic determinant for the induction of neutralizing antibodies and as an essential target for a MERS subunit vaccine [7,22-26]. Meanwhile, a previous study has identified that the most stable and neutralizing viral RBD fragment is S377-588 from the five following known versions: S350-588, S358-588, S367-588, S367-606 and S377-588 [27]. Therefore, S377-588 of the MERS-CoV S protein is potentially useful for designing an effective vaccine.

Mucosal vaccination of subunit vaccines requires antigen delivery vectors and adjuvants for optimal immune responses [28]. Displaying heterologous pathogen proteins on the surface of bacteria is a rational way to enhance the immunogenicity of a vaccine [29]. A novel surface display system contains nonliving and genetically unmodified gram-positive enhancer matrix (GEM) particles and a protein anchor (PA) from the Lactococcus lactis peptidoglycan hydrolase AcmA, which is the GEM-PA surface display system. The GEM-PA surface display system is a flexible, effective, inexpensive, and easy-to-handle alternative for heterologous proteins and peptides on GEM particles [30]; this system has been applied to parasite oral vaccines [31], Streptococcus pneumoniae mucosal vaccines [32], and porcine circovirus type 2 vaccines [33], among others.

The PA of the system surface display is the lysin motif (LysM) derived from the C-terminal peptidoglycan-binding domain of AcmA, an autolysin from Lactococcus lactis, and binds to GEM particles in a noncovalent manner [34,35]. The number of LysMs in proteins affects the efficiency of foreign proteins binding to the GEM [34]. Some studies showed that three LysM domains in fusion proteins have optimal peptidoglycan-binding activities and biological functions [36,37]. A previous study shown that two LysM domains in fusion proteins have a much stronger binding activity than the others [30]. Therefore, further study on the number of LysMs in proteins is necessary. LysM domains are often parted from the other domains and from each other through linker sequences, conveying LysM domain mobility and flexibility to the fused target protein and allowing the proteins to attain an optimal orientation in binding with the cell wall [35]. However, the linker peptides between the PA and 
antigen proteins have yet to be explored for their influence on the binding affinity and immunogenicity of the fusion protein.

Considering that the number of LysMs and linker sequences in the fusion proteins may influence PA binding efficacy to GEM particles and the immunogenicity of the antigen proteins, we expressed $\mathrm{RLP}_{2}, \mathrm{RLP}_{3}$, and $\mathrm{RP}_{3}$ based on the recombinant baculovirus expression system. Then, the fusion proteins were tested for their ability to bind to GEM particles, and the immunogenicity of the antigen proteins was tested. The mucosal immunity and systemic immune responses caused by the MERS-CoV BLP candidate vaccine were also detected through intranasal immunization in a mouse model with or without GEL01 adjuvant.

\section{Materials and Methods}

\subsection{Construction and Expression of Recombinant Baculovirus}

The construction of $r B V-R_{2} P_{2}, r B V-R P_{3}$, and $r B V-R_{3}$ was as follows: MERS-CoV RBD genes encoding $S$ glycoprotein residues 377-588 were amplified by PCR using codon-optimized S (GenBank: KF600645) as a template with oligonucleotide primers RBD-F and linker-RBD-R (Table 1). PA2 genes encoding two LysMs were amplified by PCR using codon-optimized pUC57-PA3 (L. lactis MG1363) as a template with the oligonucleotide primers linker-PA2-F and PA3-R. The PCR fragment of $\mathrm{RLP}_{2}$ was amplified by a second PCR using the last products of the RBD and PA2 genes as templates with the oligonucleotide primers RBD-F and PA3-R. The resulting construct was digested with XbaI and KpnI and then inserted into the pFastBac1-HBM plasmid (Invitrogen, Carlsbad, CA, USA) to generate the recombinant plasmid pFastBac1-RLP 2 . To construct the recombinant genes $\mathrm{RLP}_{3}$ and $\mathrm{RP}_{3}$, the genes were amplified by PCR and inserted into the pFastBac1-HBM plasmid with XbaI and KpnI digestion, generating the recombinant plasmids pFastBac1-RLP3 and pFastBac1-RP3, respectively.

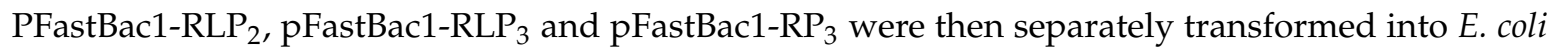
$\mathrm{DH} 10 \mathrm{Bac}$ cells to generate recombinant bacmids (rBacmid-RLP $2, \mathrm{rBacmid}-\mathrm{RLP}_{3}$ and $\mathrm{rBacmid}-\mathrm{RP}_{3}$ ). Then, the recombinant bacmids were transfected into Spodoptera frugiperda 9 (Sf9, Gibco, Grand Island, NY, USA) insect cells using liposome 3000 according to the Bac-to-Bac expression system manual (Invitrogen, USA) and cultured in 6-well plates at $2 \times 10^{6} \mathrm{cells} / \mathrm{mL}$ to generate the recombinant baculoviruses, $\mathrm{rBV}-\mathrm{RLP}_{2}, \mathrm{rBV}-\mathrm{RLP}_{3}$, or $\mathrm{rBV}-\mathrm{RP}_{3}$. Supernatants containing recombinant baculovirus were harvested at 4 days after transfection as viral stocks.

Table 1. Oligonucleotide primers used in this study.

\begin{tabular}{cc}
\hline Oligonucleotide Primers & Sequences \\
\hline RBD-F ${ }^{1,3}$ & $5^{\prime}$-TGCTCTAGACATCACCATCACCATCACCAAGCCGAAGGAGTTGAA-3' (XbaI) \\
Linker-RBD-R ${ }^{2}$ & $5^{\prime}$-ACCAGAACCACCACCAGAACCACCCAACTTAGGGCAGACGCT-3' \\
RBD-R & $5^{\prime}$-GTTACCAGCTGAAGAAGCACCATCCAACTTAGGGCAGACGCT-3' \\
PA3-F & $5^{\prime}$-ACCAATAGCGTCTGCCCTAAGTTGGATGGTGCTTCTTCAGCTGG-3' \\
Linker-PA2-F ${ }^{\prime}$ & $5^{\prime}$-GGTGGTTCTGGTGGTGGTTCTGGTACTACCGTTAAGGTGAAGTC-3' \\
Linker-PA3-F ${ }^{2}$ & $5^{\prime}$-GGTGGTTCTGGTGGTGGTTCTGGTGATGGTGCTTCTTCAGCTGG-3' \\
PA3-R ${ }^{1}$ & $5^{\prime}$-CGGGGTACCTTACTTGATACGCAGGTATTGAC-3' (KpnI) \\
\hline
\end{tabular}

${ }^{1}$ restriction enzyme sites are underlined and italicized. ${ }^{2}$ Middle linker (Gly-Gly-Ser-Gly)x2 base sequences are underlined. ${ }^{3}$ His-tag base sequences are in bold.

\subsection{Immunofluorescence Assay (IFA) and Western Blotting Analyses of Recombinant Baculoviruses}

An IFA was performed to confirm the expression of $\mathrm{RLP}_{2}, \mathrm{RLP}_{3}$ and $\mathrm{RP}_{3}$ as previously described [4]. Briefly, Sf9 cells cultured in 96-well plates at $2 \times 10^{6}$ cells $/ \mathrm{mL}$ were infected with the recombinant baculovirus. After $48 \mathrm{~h}$ of infection, the cultured plates were fixed with $80 \%$ cold acetone overnight at $-20^{\circ} \mathrm{C}$, washed three times with PBS- $0.05 \%$ Tween 20 (PBST), and then incubated with a rabbit anti-MERS-S polyclonal antibody (1:500, Sino Biological Inc, Beijing, China) containing $1 \%$ bovine serum albumin (BSA, Sigma-Aldrich, USA) at $37^{\circ} \mathrm{C}$ for $1 \mathrm{~h}$. After three washes with PBST, an FITC-labeled 
goat against rabbit IgG antibody (1:300, BioWorld, Inc, St. Louis, MN, USA) was added with Evans blue (Sigma-Aldrich, St. Louis, MN, USA) for $1 \mathrm{~h}$ at $37^{\circ} \mathrm{C}$. After washing, the cells were observed with a fluorescence microscope.

For Western blotting analysis, the culture of Sf9 cells infected with each recombinant baculovirus (rBV-RLP $2, \mathrm{rBV}^{\mathrm{RLP}} \mathrm{P}_{3}, \mathrm{rBV}-\mathrm{RP}_{3}$, and $\mathrm{rBV}$ ) was centrifuged at $6000 \times g$ at $4{ }^{\circ} \mathrm{C}$ for $15 \mathrm{~min}$, and then the culture supernatants were obtained as supernatant fractions. Cell pellets were washed three times with $10 \mathrm{mM}$ PBS (pH 7.2-7.4) and then resuspended in PBS. Samples of supernatant fractions and cell pellets were transferred onto a polyvinylidene fluoride (PVDF) membrane (Merck Millipore, Billerica, MA, USA) after SDS-PAGE under denaturing conditions for Western blotting with a rabbit anti-MERS-CoV-S polyclonal antibody.

\subsection{Binding of the Fusion Proteins to Gem Particles}

GEM particles were prepared as described in detail elsewhere [28]. In brief, cells from the L. lactis strain MG1363 were harvested and washed with PBS and then boiled in 10\% trichloroacetic acid for $30 \mathrm{~min}$, generating the so-called GEM particles. With a Bürker-Turk counting chamber, the number of GEM particles per milliliter was counted. One unit (U) was defined as $2.5 \times 10^{9} \mathrm{GEM}-+$ particles. The standard procedure was followed, and one unit of GEM particles was added into $10 \mathrm{~mL}$ of each recombinant baculovirus culture supernatant; the culture was slowly mixed on a rotary shaker at room temperature for 60 min, generating RLP2-GEM, RLP3-GEM and RP3-GEM. Then, the binding GEM particles were concentrated at $6000 \times g$ for $10 \mathrm{~min}$ at $4{ }^{\circ} \mathrm{C}$, washed and resuspended in sterile PBS, and stored at a concentration of $200 \mu \mathrm{L} / \mathrm{U}$ at $-20^{\circ} \mathrm{C}$ until further use.

\subsection{SDS-PAGE, Western Blotting and IFA Analysis of the Binding GEM Particles}

For the SDS-PAGE and Western blotting analyses of the binding GEM particles, the complexes were resuspended in 5× SDS-PAGE sample buffer (Beyotime Biotechnology, Shanghai, China), separated by $12 \%$ SDS-PAGE and then transferred by electroblotting onto PVDF transfer membranes under denaturing conditions for Western blotting with a rabbit anti-MERS-CoV-S polyclonal antibody.

For the IFA, $100 \mu \mathrm{L}$ binding GEM particles was concentrated at $6000 \times g$ for $10 \mathrm{~min}$ at $4{ }^{\circ} \mathrm{C}$ and resuspended in 3\% BSA for blocking for $30 \mathrm{~min}$ at $37^{\circ} \mathrm{C}$.Then, the binding GEM particles were incubated with a 1:200 dilution of the rabbit anti-MERS-CoV-S polyclonal antibody in PBS with $1 \%$ BSA for $60 \mathrm{~min}$ at $37^{\circ} \mathrm{C}$. After three washes, the complexes were incubated with an FITC-labeled goat anti-rabbit IgG antibody for $1 \mathrm{~h}$ at $37^{\circ} \mathrm{C}$ and then viewed and photographed using a Zeiss microscope with incident UV illumination and the Zeiss Axiovision digital imaging system (Zeiss, Oberkochen, Germany).

For the maximum binding capacity of each fusion protein binding the GEM particles, $0.5 \mathrm{U}$ GEM particles were incubated for $60 \mathrm{~min}$ at room temperature with $0,2,4,6,8$ and $10 \mathrm{~mL}$ of each recombinant baculovirus culture supernatant. Then, SDS-PAGE was used to analyze each fusion protein binding the GEM particles with Gel Image System analysis software, version 4.2 (Tanon, Shanghai, China). Meanwhile, the amount of each fusion protein binding the GEM particles was determined densitometrically by analysis of scans of Coomassie brilliant blue-stained SDS-12\% polyacrylamide (PAA) gels with the Quantity One image analysis software, version 4.6.7. A calibration curve was generated using BSA protein standards on the same PAA gel.

\subsection{Immunizations and Samples Collection}

A total of two batches of BALB/c mice (6 weeks old, female) were procured from the Changchun Yisi Laboratory Animal Technology Co., Ltd. (Changchun, China) and were immunized. In Batch I, twenty mice were randomly distributed into four groups ( $n=5$ per group) and vaccinated intramuscularly (IM). Mice in group 1 were vaccinated with PBS as a control; mice in group 2 were vaccinated with GEM adjuvanted with a complex of ISA201VG (Seppic, Paris, France) and PolyI:C (Sigma, St. Louis, MN, USA) as a control; mice in group 3 were vaccinated with $5 \mu \mathrm{g} \mathrm{RP}_{3}$-GEM antigen proteins adjuvanted 
with the same in group 2; mice in group 4 were vaccinated with $5 \mu \mathrm{g} \mathrm{RLP}_{3}$-GEM antigen proteins adjuvanted with the same in group 2. All the groups were boosted twice with the same 3-week intervals. Blood samples were collected at two, five and eight weeks postimmunization (wpi).

In Batch II, thirty mice were randomized into three groups and vaccinated intranasally (IN). Mice in group 1 were vaccinated with PBS as a control; mice in group 2 were vaccinated with $5 \mu \mathrm{g}$ $\mathrm{RLP}_{3}$-GEM antigen proteins; mice in group 3 were vaccinated with $5 \mu \mathrm{g} \mathrm{RLP}_{3}$-GEM antigen proteins mixed with $10 \mu \mathrm{L}$ GEL01 adjuvant (Seppic, Paris, France). All the groups were boosted twice with the same 3-week intervals. Blood samples were collected at two, five and eight weeks wpi. Serum samples were inactivated at $56^{\circ} \mathrm{C}$ for $30 \mathrm{~min}$ prior to analysis. The lung lavage samples were collected with $1 \mathrm{~mL}$ cold PBS, and the gut-wash samples were collected with $2 \mathrm{~mL}$ cold PBS on ice at eight wpi. The sera, lung lavage and gut-wash sample supernatants were collected after centrifugation at $6000 \times g$ for $15 \mathrm{~min}$ at $4{ }^{\circ} \mathrm{C}$ and were stored at $-80^{\circ} \mathrm{C}$ for further use.

\subsection{Pseudotyped Virus Neutralization Assay}

A pseudotyped virus neutralization assay was performed as described previously [38]. In brief, $100 \times$ TCID $_{50}$ of MERS-pseudotyped virus was mixed with an equal volume of serially diluted mouse sera, and the mixtures were incubated at $37^{\circ} \mathrm{C}$ for $30 \mathrm{~min}$ and then incubated with Huh 7 cells for $4 \mathrm{~h}$. Each sample was assayed in quadruplicate. The incomplete medium was replaced with complete DMEM (10\% fetal bovine serum $+1 \%$ penicillin-streptomycin), and then the samples were incubated at $37^{\circ} \mathrm{C}$ for $48 \mathrm{~h}$. The luciferase activity of the samples was measured with an Infinite M200 Microplate Spectrophotometer (Tecan, Männedorf, Switzerland).

\subsection{Enzyme-Linked Immunosorbent Assay (ELISA) Measurement of RBD-Specific Antibodies}

The lung lavage, gut-wash and sera samples from the animals were collected at eight wpi and tested for RBD-specific IgA, IgG, IgG1 and IgG2a antibodies by an ELISA. Briefly, purified RBD antigen produced in E.coli $(1 \mu \mathrm{g} / \mathrm{mL})$ in $100 \mu \mathrm{L}$ carbonate buffer was used to coat 96-well microtiter plates (Corning-Costar, Corning, NY, USA) overnight at $4{ }^{\circ} \mathrm{C}$. Following three washes with PBST and blocking with PBST containing 3\% BSA for $2 \mathrm{~h}$ at $37^{\circ} \mathrm{C}$, the plates were incubated with 2-fold serial dilutions of samples in PBS containing $0.5 \%(w / v)$ BSA at $37^{\circ} \mathrm{C}$ for $1 \mathrm{~h}$. After three wash cycles with PBST, the plates were incubated with the following HRP-labeled goat antibodies: anti-mouse IgA (1:2000, SouthernBiotech, Birmingham, AL, USA), anti-mouse IgG (1:2000, BioWorld, St. Louis, MN, USA), anti-mouse IgG1 (1:2000, Southern Biotech, USA), and anti-mouse IgG2a (1:2,000, SouthernBiotech, Birmingham, AL, USA) at $37^{\circ} \mathrm{C}$ for $1 \mathrm{~h}$. Subsequently, the plates were washed three times and $100 \mu \mathrm{L}$ tetramethylbenzidine substrate was added per well; the color development was stopped by adding $50 \mu \mathrm{L} /$ well $\mathrm{H}_{2} \mathrm{SO}_{4}$. Optical density values were measured at $450 \mathrm{~nm}$ using an ELISA plate reader (Bio-Rad, Hercules, CA, USA).

\subsection{ELISpot IFN- $\gamma$ and IL-4 Cytokine Assays}

ELISpot IFN- $\gamma$ and IL-4 cytokine assays were performed as described previously [9]. Splenocytes were harvested in complete RPMI 1640 medium at 7 days after the third immunization and plated in a 96-well ELISpot plate (MABTECH, Nacka, Sweden). Purified RBD antigen produced in E.coli was or was not added to each well at a final concentration of $10 \mu \mathrm{g} / \mathrm{mL}$ to stimulate cytokine production. After incubation for $40 \mathrm{~h}$, IFN- $\gamma$ and IL-4 were detected using mouse enzyme-linked immunospot (ELISpot) kits according to the manufacturer's instructions. Spot-forming cells (SFCs) were counted with an ELISpot reader (Multispotreader Spectrum, AID, Strasberg, Germany).

\subsection{Splenocyte Proliferation Assay}

The splenocyte proliferation assay was performed as described [39]. In brief, splenocytes were stimulated with or without purified RBD antigen $(10 \mu \mathrm{g} / \mathrm{mL})$ produced in E.coli at a concentration of $2.5 \times 10^{6}$ cells/mL in triplicate $(100 \mu \mathrm{L} /$ well $)$ in a 96 -well plate. After incubation at $37{ }^{\circ} \mathrm{C}$ and $5 \% \mathrm{CO}_{2}$ 
for $44 \mathrm{~h}, 10 \mu \mathrm{L}$ of CCK-8 solution (KeyGEN Biotech, Nanjing, China) was added to each well. After incubation for an additional $4 \mathrm{~h}$, the plates were measured at $450 \mathrm{~nm}$ using an Infinite M200 Microplate Spectrophotometer. The formula for the proliferation index (PI) was expressed as follows:

$\mathrm{PI}=(\mathrm{OD}$ for stimulated cultures $-\mathrm{OD}$ for non-stimulated cultures $) /(\mathrm{OD}$ for non-stimulated cultures - OD for control cultures).

\subsection{Evaluation of B Cell and T Cell Activation by Flow Cytometry}

Frequencies of activated B cells and T cells in splenocytes were evaluated by flow cytometry. Splenocytes were cultured in complete RPMI 1640 and stimulated with RBD antigen $(10 \mu \mathrm{g} / \mathrm{mL})$ produced in E.coli for $60 \mathrm{~h}$. Cells were then stained with the following anti-mouse antibodies: APC-anti-CD19, FITC-anti-CD4, PE-anti-CD8, PE/Cy7-anti-CD69 (BD Biosciences, San Jose, CA, USA). After washing, the labeled cell samples were examined by a FACSAriaTM Cell Sorter (BD Biosciences, San Jose, CA, USA).

\subsection{ELISA Measurement of Cytokine Levels in Splenocyte Culture Supernatants}

Splenocytes were harvested 7 days after the third immunization and stimulated with RBD antigen $(10 \mu \mathrm{g} / \mathrm{mL})$ produced in E.coli for $72 \mathrm{~h}$ at $37^{\circ} \mathrm{C}$ and $5 \% \mathrm{CO}_{2}$. The supernatant was collected by centrifugation $(600 \times g, 10 \mathrm{~min})$. T helper 1 (Th1) cytokines (tumor necrosis factor [TNF]- $\alpha$, interferon [IFN]- $\gamma$, and interleukin [IL]-2) and Th2 cytokines (IL-4, IL-6, and IL-10) in the supernatants were detected using mouse ELISA cytokine kits (MABTECH, Nacka, Sweden) according to the manufacturer's instructions.

The purified RBD antigen has been tested to produce similar background responses in PBS or GEM immunized animals.

\subsection{Data Analysis}

The results are expressed as the means \pm SD. Figures were generated using GraphPad Prism 8.0 software (GraphPad Software Inc.). Significance differences between the groups were analyzed using one-way ANOVA and were deemed significant at $P$ values of 0.05 or less.

\subsection{Laboratory Facility and Ethics Statement}

The treatment of all mice was in accordance with the welfare and ethical guidance of Chinese laboratory animals (GB 14925-2001). The agreement was approved by the Animal Welfare and Ethics Committee of the Institute of Veterinary Medicine of the Military Academy of Sciences (Laboratory Animal Care and Use Committee Authorization, permit number JSY-DW-2018-02).

\section{Results}

\subsection{Expression of Fusion Proteins}

The strategy for designing $\mathrm{RLP}_{2}, \mathrm{RLP}_{3}$, and $\mathrm{RP}_{3}$ fusion proteins is shown in Figure $1 \mathrm{a}, \mathrm{b}$, in which RBD was fused to PA2 and PA3 with or without a linker. The IFA results showed that compared to the control cells, the Sf9 cells expressing $\mathrm{RLP}_{2}, \mathrm{RLP}_{3}$, and $\mathrm{RP}_{3}$ proteins emitted strong green fluorescence signals with an anti-MERS-S polyclonal antibody for RBD, suggesting that the expressed fusion proteins have good antigenicity (Figure 1c-g). Furthermore, Western blotting analysis showed that the RLP ${ }_{2}$, $\mathrm{RLP}_{3}$ and $\mathrm{RP}_{3}$ recombinant proteins were successfully expressed as soluble proteins and secreted into the supernatants (Figure $1 \mathrm{~h}-\mathrm{j}$ ). 
(a)

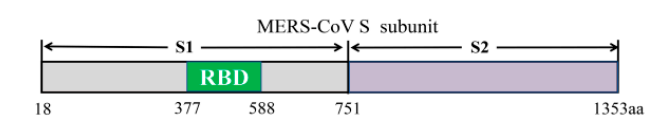

(b)

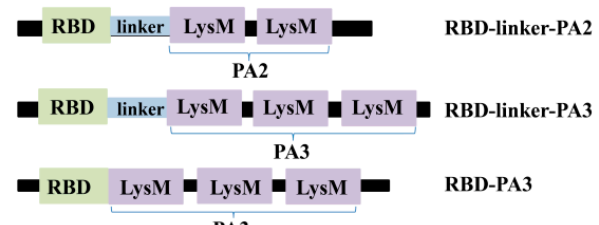

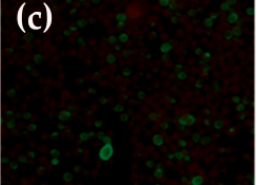

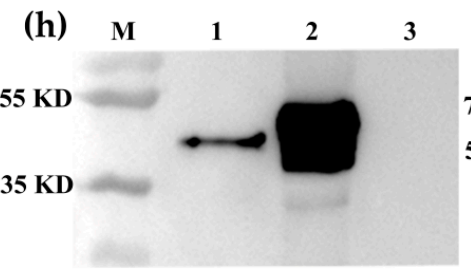

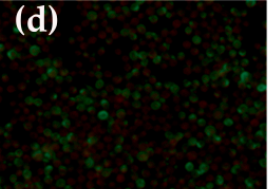

(i) $\mathrm{M}$

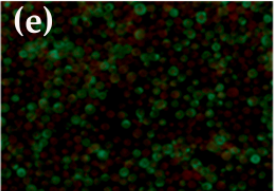

$70 \mathrm{KD}$ $55 \mathrm{KD}$

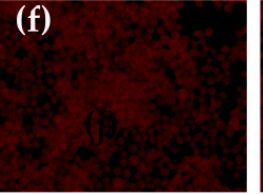

$\begin{array}{lllll}\text { (j) } & \text { M } & 1 & 2 & 3\end{array}$

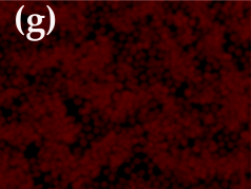

Figure 1. Construction and detection of the fusion proteins expression in baculovirus-infected Sf9 insect cells. (a) Schematic illustration of the MERS-CoV-S subunit; (b) Schematic illustration of RBD-linker-PA2, RBD-linker-PA3, and RBD-PA3 fusion proteins; (c-g) IFA detection of the RLP , $^{2}$ $\mathrm{RLP}_{3}$, and $\mathrm{RP}_{3}$ expression in baculovirus-infected Sf9 insect cells (Magnification of microscopy images, $\times 200)$. Cells were infected with $r B V-R L P_{2}, r B V-R L P_{3}, r B V-R_{3}$ in (c-e); cells infected with $\mathrm{rBV}(\mathbf{f})$ and uninfected cells (g) were the mock cells. After $48 \mathrm{~h}$, cells were detected with a rabbit anti-MERS-S

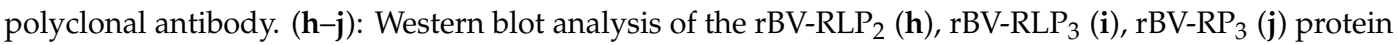
expression in Sf9-infected cells. Expression was detected with a rabbit anti-MERS-S polyclonal antibody. M: molecular weight marker, 1: culture supernatant, 2: cell sedimentation, 3: rBV infected cells.

\subsection{Location of Fusion Proteins on GEM Particles}

The surface location of $\mathrm{RLP}_{2}, \mathrm{RLP}_{3}$ and $\mathrm{RP}_{3}$ fusion proteins on GEM particles was analyzed by SDS-PAGE (Figure 2a), Western blotting (Figure 2b) and IFA with an anti-MERS-S polyclonal antibody (Figure 2c-f). SDS-PAGE and Western blotting observations showed that the $\mathrm{RLP}_{2}, \mathrm{RLP}_{3}$ and $\mathrm{RP}_{3}$ fusion proteins were bound to GEM particles. Meanwhile, immunofluorescence microscopy observations showed that compared to the GEM particles (negative control), the combination of the GEM particles and fusion proteins emitted a strong green fluorescence. Therefore, the above results indicated that the $\mathrm{RLP}_{2}, \mathrm{RLP}_{3}$ and $\mathrm{RP}_{3}$ fusion proteins were anchored to GEM particles.

\subsection{Binding Activity of Fusion Proteins on GEM Particles}

To investigate whether the differences in binding activity on GEM particles were caused by differences in LysM repeats and the extension of anchor proteins plus a linker to the RBD, direct binding capacity studies on GEM particles was performed by SDS-PAGE (Figure 3). To analyze the maximum binding capacity of each fusion protein binding the GEM particles, 0.5 U GEM particles were combined with $0,2,4,6,8$ and $10 \mathrm{~mL}$ of each recombinant baculovirus culture supernatant. According to the relative binding quantity on the Coomassie brilliant blue-stained polyacrylamide gels, with the increase in binding culture supernatant volume of $0.5 \mathrm{U}$ GEM particles, the relative quantity of binding fusion proteins increased, and the relative quantity of all fusion proteins in $8 \mathrm{~mL}$ and $10 \mathrm{~mL}$ volumes was similar; this result suggests that the GEM particles binding the fusion proteins have been saturated. Furthermore, we estimated that 1U GEM particles can bind $133.2 \mu \mathrm{g}$ of the RLP $\mathrm{P}_{2}$ fusion protein, $217.76 \mu \mathrm{g}$ of the $\mathrm{RLP}_{3}$ fusion protein and $191.86 \mu \mathrm{g}$ of the $\mathrm{RP}_{3}$ fusion protein with the Quantity One image analysis software. The above results indicated that the binding activities of $\mathrm{RLP}_{3}$ and $\mathrm{RP}_{3}$ were better than those of $\mathrm{RLP}_{2}$; thus, $\mathrm{RLP}_{3}$ and $\mathrm{RP}_{3}$ were selected for further experiments in mice. 


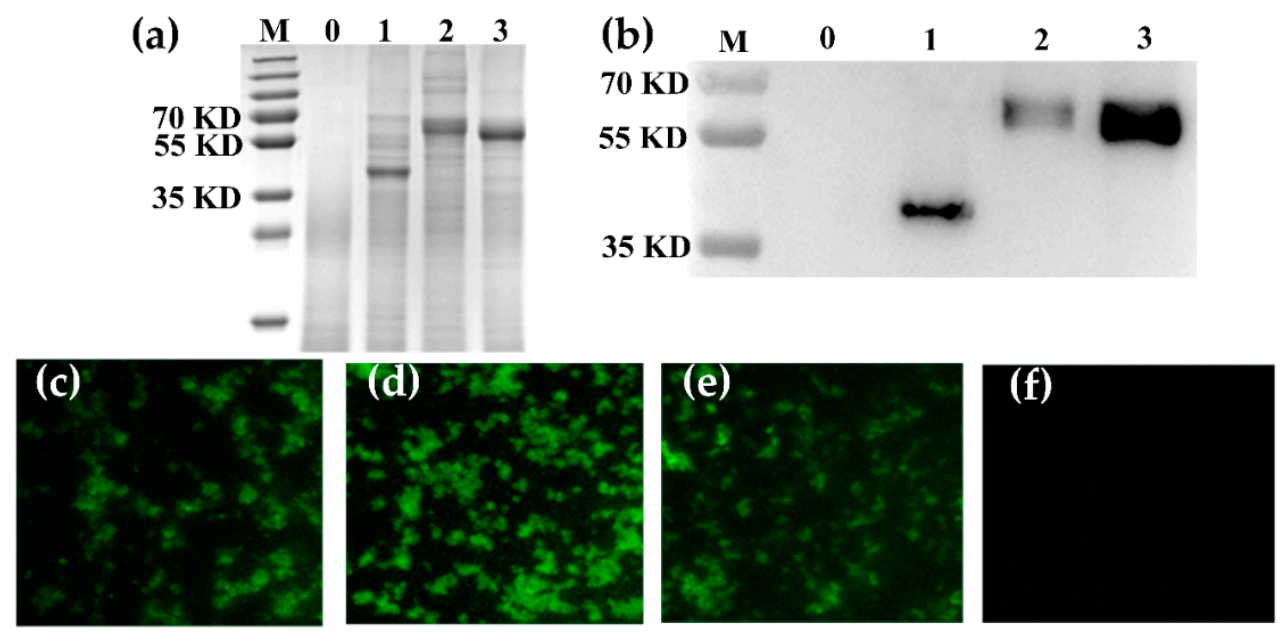

Figure 2. Detection of the fusion proteins displaying the GEM particles. (a) SDS-PAGE analysis of the displaying of $\mathrm{RLP}_{2}, \mathrm{RLP}_{3}$, and $\mathrm{RP}_{3}$ proteins on GEM particles. Lane 1: GEM particles displaying $\mathrm{RLP}_{2}$ from the culture supernatant of $\mathrm{rBV}-\mathrm{RLP}_{2}$-infected Sf9 cells; Lane 2: GEM particles displaying $\mathrm{RLP}_{3}$ from the culture supernatant of $\mathrm{rBV}-\mathrm{RLP}_{3}$-infected Sf9 cells; Lane 3: GEM particles displaying $\mathrm{RP}_{3}$ from the culture supernatant of $\mathrm{rBV}-\mathrm{RP}_{3}$-infected Sf9 cells; Lane 0: GEM particles; M: molecular weight marker. (b) Western blot analysis of the proteins displayed on GEM particles. Lane 1, Lane 2, Lane 3, and Lane 0 are the same as in Figure 2a. (c-f) Representative fluorescence microscopy images showing that fusion proteins were loaded on GEM particles (Magnification of microscopy images, $1000 \times)$. GEM particles were bound with $\mathrm{RLP}_{2}(\mathbf{c}), \mathrm{RLP}_{3}(\mathbf{d})$, and $\mathrm{RP}_{3}(\mathbf{e})$ proteins and were the mock control (f); proteins were detected with a rabbit anti-MERS-S polyclonal antibody.

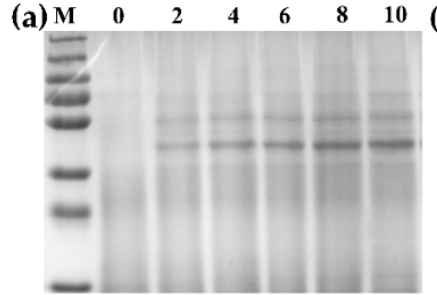

(d)

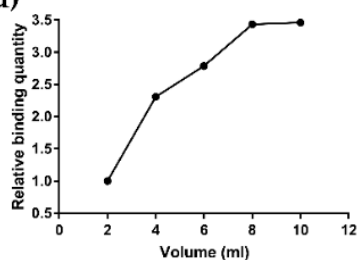

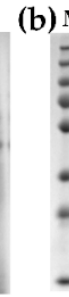

(e)
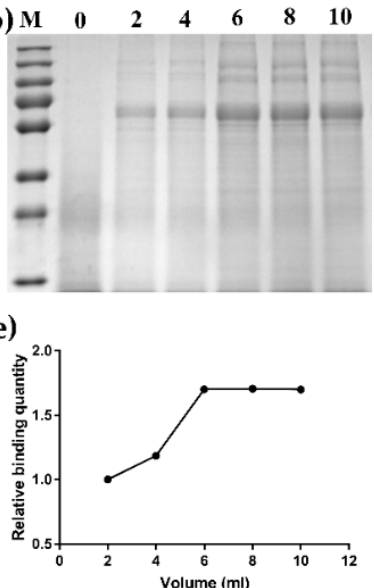

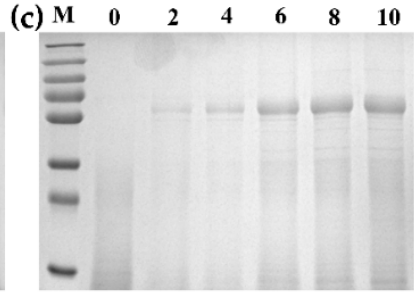

(f)

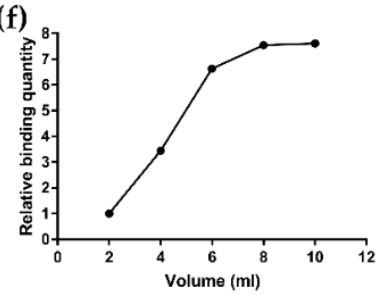

Figure 3. Detection of binding activity of the fusion proteins on GEM particles by SDS-PAGE. (a-c) The maximum binding capacity of each fusion proteins binding to the GEM particles when 0.5 U GEM particles was combined with $0,2,4,6,8$ and $10 \mathrm{~mL}$ of each recombinant baculovirus culture supernatant. (a) $\mathrm{RLP}_{2}$-GEM; (b) $\mathrm{RLP}_{3}$-GEM; (c) $\mathrm{RP}_{3}$-GEM. (d-f) The relative binding quantity of binding fusion proteins on the GEM particles was detected densitometrically by analysis of scans of PAA gels with Gel Image System analysis software (Tanon, China). M: molecular weight marker; 0: GEM particles.

\subsection{Virus Neutralizing Antibodies and ELISA Measurement of Subtype Antibodies in Serum}

Antibody responses in the serum to MERS-CoV were measured by a pseudotyped virus neutralization assay and shown as end-point dilution titers at two, five, and eight wpi. To enhance the immune response of the $\mathrm{RLP}_{3}-\mathrm{GEM}$ and $\mathrm{RP}_{3}-\mathrm{GEM}$ in mice, we applied a complex of ISA201VG and PolyI:C as adjuvants that we screened out in mice through intramuscular administration in our laboratory. The results showed that the antibody levels of the sera from the $\mathrm{RLP}_{3}-\mathrm{GEM}$ and 
$\mathrm{RP}_{3}$-GEM-immunized mice gradually increased to plateau at eight weeks, and there were significant differences in the neutralizing activities between the two groups at two and five weeks (Figure 4a). These results suggested that the immunogenicity of $\mathrm{RLP}_{3}$-GEM was stronger than that of $\mathrm{RP}_{3}$-GEM, and thus, $\mathrm{RLP}_{3}$-GEM was selected for further intranasally vaccinated experiments in mice.

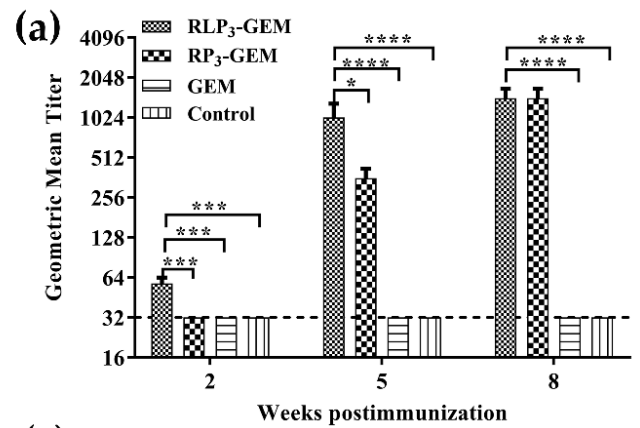

(c)

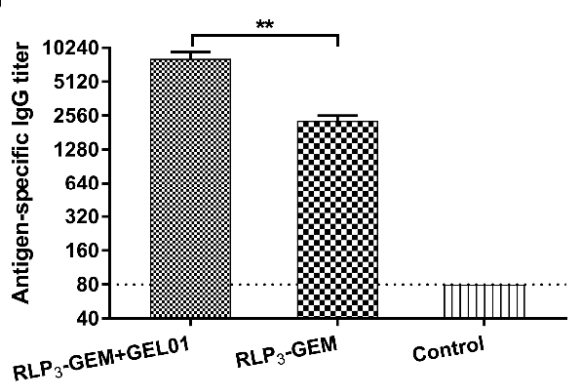

(b)

(e)
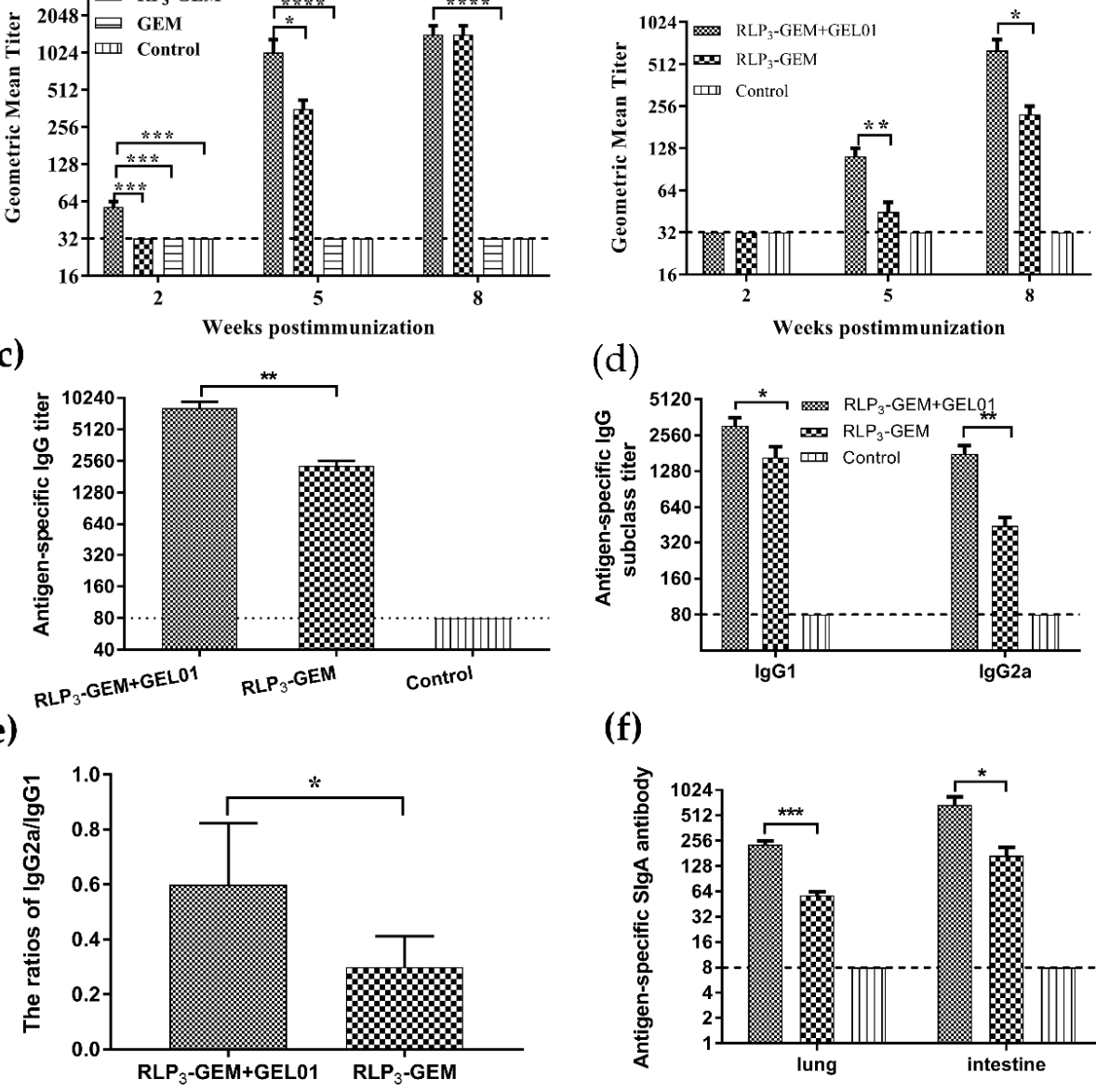

(f)

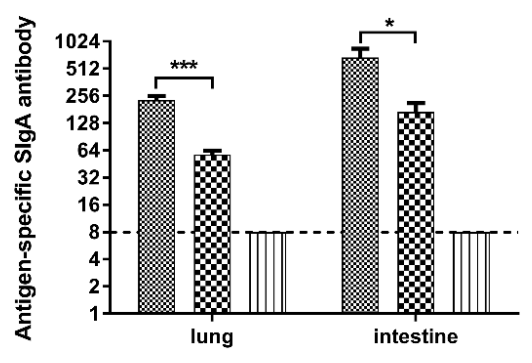

Figure 4. Detection of antibody levels in the serum and mucosa from the immunized mice. Serum samples were collected at weeks two, five, and eight. Neutralizing antibody titers in the serum at weeks two, five, and eight were performed by a MERS-CoV pseudotyped virus neutralization assay. Antigen-specific IgG, IgG1, IgG2a and IgA antibody levels in the serum or in mucosa at week 8 were assessed by indirect ELISA with the purified RBD protein, displaying as the end-point dilution titers. The horizontal dotted line in the figure indicates the limit of determination (LOD). $n=5$ mice/group/time point. Data are shown as the means \pm SD and were analyzed by one-way ANOVA $\left(* p<0.05 ; * * p<0.01 ; * * * p<0.001\right.$; ${ }^{* * * *} p<0.0001$ ). (a) The neutralization titers of serum samples from mice immunized intramuscularly at the indicated times with $\mathrm{RLP}_{3}$-GEM and $\mathrm{RP}_{3}$-GEM. (b) The neutralization titers of serum samples from mice immunized intranasally with RLP3-GEM and $\mathrm{RLP}_{3}$-GEM+GEL01 at the indicated times. (c-e) RBD-specific IgG (c), IgG1 (d) and IgG2a (d) titers in the serum from mice immunized intranasally at week 8 . Ratios of IgG2a/IgG1 (e) were calculated. (f) The local immune responses from mice intranasally immunized with RLP $_{3}$-GEM and RLP ${ }_{3}$-GEM+GEL01. Antigen-specific mucosal IgA titers in lung lavage fluid and intestine washes of immunized mice at week 8.

To analyze whether intranasally $\mathrm{RLP}_{3}$-GEM-immunized mice could produce systemic humoral immune responses, specific serum antibody levels were determined by a pseudotyped virus neutralization assay and ELISA. GEL01 is a commercial adjuvant based on a polymer technology, already applied in the adjuvant for veterinary vaccine field, and can be used in parenteral and mucosal 
immunity. To decide whether the GEL01 could enhance the immune response of the $\mathrm{RLP}_{3}$-GEM in mice or not, we intranasally immunized mice with it. Pseudotyped virus neutralization assay data showed that $\mathrm{RLP}_{3}$-GEM and $\mathrm{RLP}_{3}$-GEM plus GEL01 induced strong neutralization against an MERS-CoV infection, and the latter displayed a much higher neutralizing titer than the former (Figure $4 \mathrm{~b}$ ). A similar phenomenon was also found for the RBD-specific IgG (Figure 4c), IgG1 (Figure 4d), and IgG2a (Figure 4d) antibodies in the sera at eight wpi caused by $\mathrm{RLP}_{3}$-GEM and $\mathrm{RLP}_{3}$-GEM plus GEL01. Meanwhile, the ratios of IgG2a/IgG1 of RLP3-GEM plus GEL01 were much higher than those of $\mathrm{RLP}_{3}$-GEM (Figure 4e), suggesting that GEL01 could induce a Th1-polarized immune response. Collectively, these data showed that $\mathrm{RLP}_{3}$-GEM could induce systemic immune responses and that the adjuvant GEL01 could significantly enhance antibody responses.

\subsection{Mucosal IgA Levels in Lungs and Intestines}

To verify whether $\mathrm{RLP}_{3}$-GEM could produce local immune responses in intranasally immunized mice, specific IgA levels in lung lavage fluid and intestinal washes were determined by ELISA at eight wpi. The data showed that mucosal IgA levels were present among some of the tissues and organs in the $\mathrm{RLP}_{3}$-GEM and $\mathrm{RLP}_{3}$-GEM plus GEL01 groups, and the IgA levels were more obvious in the $\mathrm{RLP}_{3}$-GEM plus GEL01 group (Figure 4f). These results showed that mucosal immune responses were induced by the $\mathrm{RLP}_{3}$-GEM candidate vaccine, and the effect was significantly increased by the adjuvant GEL01.

\subsection{Splenocyte Proliferation by ex vivo Restimulation}

To analyze the effects of GEL01 on splenocyte proliferative responses, an ex vivo splenocyte proliferation assay was performed. Under the stimulation of RBD proteins, splenocytes harvested from mice intranasally immunized with $\mathrm{RLP}_{3}$-GEM plus GEL01 proliferated more efficiently than those from mice immunized with $\mathrm{RLP}_{3}$-GEM without GEL01 (Figure 5a). Therefore, these data suggested that GEL01 could evoke potent antigen-specific immune responses.

\subsection{Splenocyte Activation Assays}

CD69 is an activation marker of effector immune cells [40]. Therefore, we detected the frequencies of $\mathrm{CD} 9^{+}$in splenocytes collected from immunized mice with flow cytometry to analyze the activation of B cells, CD4 ${ }^{+} \mathrm{T}$ cells and CD8 ${ }^{+} \mathrm{T}$ cells. The expression of CD69 on B cells (Figure $5 \mathrm{~b}$ ), CD4 ${ }^{+} \mathrm{T}$ cells (Figure $5 \mathrm{c}$ ) and $\mathrm{CD} 8^{+} \mathrm{T}$ cells (Figure $5 \mathrm{~d}$ ) from mice immunized with $\mathrm{RLP}_{3}$-GEM with GEL01 significantly increased compared with the expression of cells from mice immunized with $\mathrm{RLP}_{3}$-GEM. These results suggested that $\mathrm{RLP}_{3}$-GEM with GEL01 induced a more potent immune activation than did $\mathrm{RLP}_{3}$-GEM, which is very important to initiate the whole immune response.

\subsection{Cytokine Secretion by Restimulated Splenocytes}

Since we analyzed whether $\mathrm{RLP}_{3}$-GEM with GEL01 displayed better efficacy than $\mathrm{RLP}_{3}$-GEM in splenocyte proliferative responses and splenocyte activation with ex vivo restimulated splenocytes, we next detected whether $\mathrm{RLP}_{3}$-GEM with GEL01 could also promote cytokine secretion profiles in immunized mice. Splenocytes were collected from immunized mice and were ex vivo restimulated with RBD; then, the Th1 (IFN-r, TNF-a, and IL-2) and Th2 (IL-4, IL-6, and IL-10) cytokines in the supernatants were detected by ELISA. The levels of these cytokines in the RLP ${ }_{3}$-GEM with GEL01 group were significantly higher than those in the $\mathrm{RLP}_{3}$-GEM group (Figure 6). The ELISpot assay showed that the amount of splenocytes secreting IFN-r and IL-4 was also remarkably increased in the $\mathrm{RLP}_{3}$-GEM with GEL01 group, similar to the results of the ELISA. Overall, the above data showed that $\mathrm{RLP}_{3}$-GEM with GEL01 induced the secretion of the Th1 and Th2 cytokines, suggesting a stronger immune response than $\mathrm{RLP}_{3}$-GEM. 
(a)

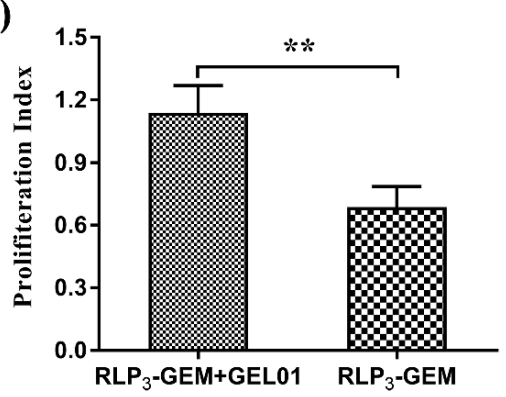

(c)

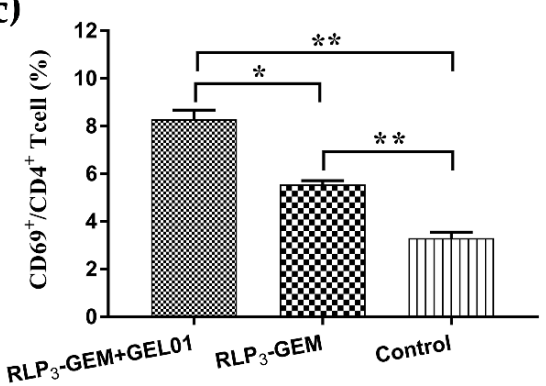

(b)

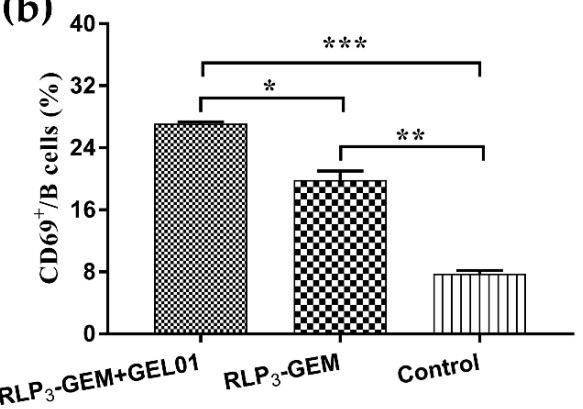

(d)

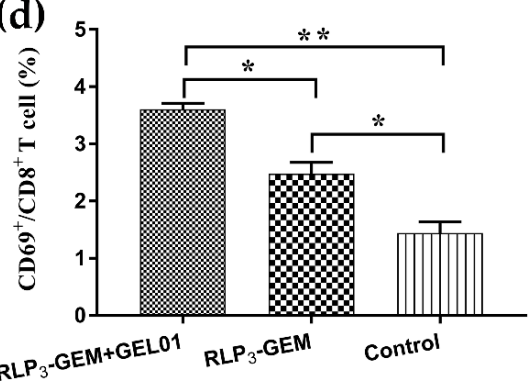

Figure 5. Index of lymphocytes and activated $\left(\mathrm{CD} 69^{+}\right) \mathrm{B}$ cells, $\mathrm{CD} 4^{+}$and $\mathrm{CD} 8^{+} \mathrm{T}$ cells harvested from the spleen. At 7 days after the last immunization, lymphocytes from mice immunized intranasally were harvested and re-stimulated with RBD $(10 \mu \mathrm{g} / \mathrm{mL})$ in vitro. The proliferative index of the spleen was detected using a CCK-8 assay. The frequency of $\mathrm{CD} 69^{+} \mathrm{CD} 19^{+} \mathrm{B}$ cells, $\mathrm{CD} 69^{+} \mathrm{CD} 4^{+} \mathrm{T}$ cells and $\mathrm{CD} 9^{+} \mathrm{CD} 8^{+} \mathrm{T}$ cells was estimated by flow cytometry. Data in $(\mathbf{a}-\mathbf{d})$ are expressed as the mean $\pm \mathrm{SD}$ for each group. ${ }^{*} p<0.05 ;{ }^{* *} p<0.01 ;{ }^{* * *} p<0.001$.

(a)

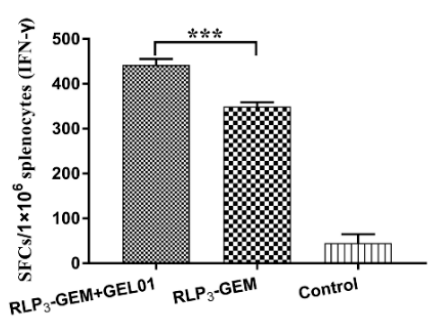

(b)

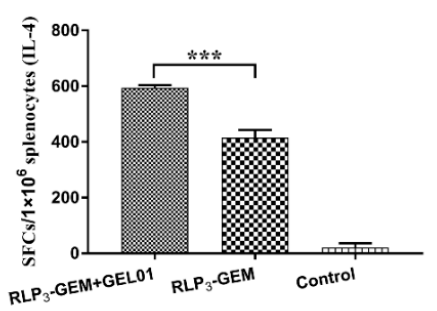

(c)

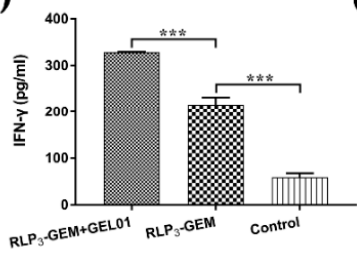

(d)

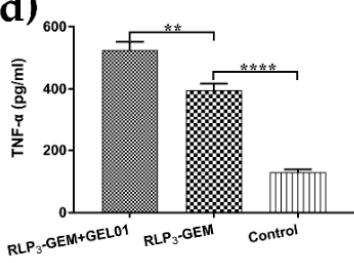

(e)

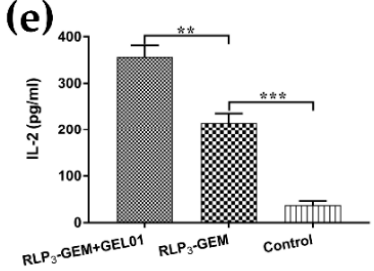

(f)

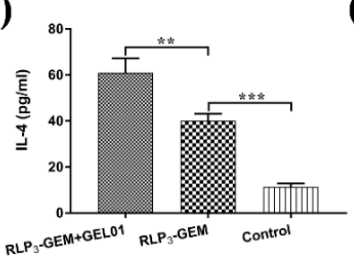

(g)

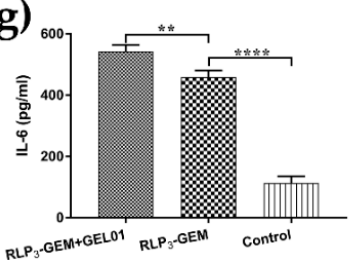

(h)

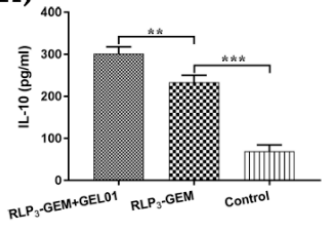

Figure 6. Detection of cytokine secretion levels in splenocytes. Splenocytes were harvested from mice immunized intranasally at 7 days after the last immunization and restimulated with RBD $(10 \mu \mathrm{g} / \mathrm{mL})$ in culture ex vivo. Splenocytes secreting IFN-r $(\mathbf{a})$ and IL-4 (b) were quantified using an ELISpot assay. Furthermore, the concentrations of IFN-r (c), TNF-a (d), IL-2 (e), IL-4 (f), IL-6 (g), and IL-10 (h) in the supernatant were measured with commercial ELISA kits. Data are expressed as the mean \pm SD. ${ }^{*} p<0.05 ;{ }^{* *} p<0.01 ;{ }^{* * *} p<0.001$. 


\section{Discussion}

Because MERS-CoV causes human respiratory infections with a high mortality rate and human-to-human transmission [41], the development of effective MERS-CoV vaccines, especially subunit-based vaccines, will provide the safest way of preventing the continuous dissemination of MERS-CoV in humans and camels [21]. Previous results showed that MERS-CoV RBD-based subunit vaccines have displayed effective immunogenicity against MERS-CoV challenges in mice $[6,22,24]$. Some studies have shown that the recombinant RBD of MERS-CoV spike protein with intranasal vaccination induced more robust local mucosal immune responses in the lung and stronger systemic cellular immune responses than that with subcutaneous vaccination in mice, demonstrating that intranasal RBD-based subunit vaccines are a safe and effective means to prevent MERS-CoV infections [42]. A study demonstrated that MERS-CoV could replicate robustly in human primary intestinal epithelial cells, intestinal organoids, and small intestine explants and could resist fed-state gastrointestinal fluids, causing enteric MERS-CoV infection [8]. Therefore, it is extremely important for MERS-CoV vaccination to induce respiratory and gastrointestinal mucosal immunity. In this study, we developed RBD-based MERS-CoV subunit vaccines with a novel bacterial antigen display system and evaluated the immunogenicity of specific mucosal immunity in lung and intestinal mucosa and the systemic immune responses due to immunization via the intranasal route.

A novel method for surface display of an antigen is based on the nonrecombinant and nonliving Lactococcus lactis bacteria-assigned GEM particles. Lactococcus lactis has a long history of use in foods and is recognized as safe [43]. The particles boiled in acids mainly consist of bacterial-shaped peptidoglycan spheres, lack other cell wall components and intracellular materials and are recognized as being especially safe [28]. The particles can bind to exogenous antigens by a PA with a high affinity and a high loading capacity [30]. In addition to the above advantages, the particles can bind to the chimeric anchor fusion proteins in culture medium at room temperature in an efficient, strong, and selective manner; the particles can only need a one-step centrifugation process to obtain the purified fusion proteins without the extra purification steps [31]; it is easier to obtain purified antigens in a bacterium-like particles vaccine compared with the virus-like particles vaccine. The GEM-PA system has been applied in a variety of animal models and has shown strong antigen-specific systemic immune responses with parenteral vaccination and both robust local and systemic responses induced by mucosal vaccination; this system has even proven to be protective against specific pathogens, including parasites, bacteria and viruses [33,44-48]. Our results showed that the MERS-CoV RBD proteins were successfully displayed on the surface of the GEM particles with the GEM-PA system.

In this GEM-PA system, PA is the LysM from the C-terminal peptidoglycan-binding domain of AcmA, an autolysin from Lactococcus lactis, and binds to GEM particles in a noncovalent manner. One of the important factors determining the binding activity of fusion proteins is the number of LysMs. In the wild, the number of LysM domains in the proteins differs greatly [49]. In the current study, the optimal number of LysM domains in the GEM-PA system for proper function are different in different groups [30,36,37]. The possible reason for this was that fusion proteins fused to different target proteins. Our results showed that the binding activity of $\mathrm{RLP}_{3}$ was remarkably higher than that of $R L P_{2}$ in GEM particles, which is consistent with the results of Kenji Okano and Anton Steen [36,50]. LysM domains are often separated from the other domains and from each other through linker sequences, raising speculation about LysM domain mobility and flexibility to the fused target proteins and allowing the proteins to attain an optimal orientation in binding with the cell wall [35]. Our results showed that the binding activity of $\mathrm{RLP}_{3}$ was slightly higher than that of $\mathrm{RP}_{3}$. Furthermore, there were significant differences in the neutralizing activity among the sera of mice intramuscularly immunized with $\mathrm{RLP}_{3}$-GEM and $\mathrm{RP}_{3}$-GEM. These results clearly suggested that the linker peptides between the PA and RBD proteins could increase the binding capacity of the PA and the immunogenicity of the RBD in the fusion proteins. Consistent with those results, linkers in the recombinant fusion proteins could improve the biological activity of functional domains [51]. Thus, this study represents a significant advancement in the development of the GEM-PA system. 
MERS-CoV transmission from camels to humans is via respiratory droplets or saliva during direct contact with infected camels or through the consumption of contaminated camel milk or meat [8]. A more effective MERS-CoV vaccine should not only provide protection against the invasion of MERS-CoV in the blood but also provide protection against invasive infections in the respiratory tract and gastrointestinal tract. Therefore, developing an MERS-CoV alternative vaccine with mucosal immune responses is necessary. In this study, we further demonstrated that $\mathrm{RLP}_{3}$-GEM was a promising candidate for intranasal immunization with the MERS-CoV subunit vaccine. Moreover, we used GEL01 as an adjuvant for intranasal vaccination. This is because GEL01, a polymer of a sodium polyacrylate-based adjuvant, can enhance the protective effects of live vaccines through mucosal immunity [52]. Our results showed that RLP $_{3}$-GEM (PLPs) induced strong neutralization against MERS-CoV pseudotyped virus infections and RBD-specific IgG, IgG1, and IgG2a antibody responses in sera, and these responses also significantly increased in the presence of the GEL01 adjuvant. IgG2a is the most effective in activating immune cells, and the ratios of IgG2a/IgG1 indicate Th1/Th2 polarization [53]. Moreover, the ratio of IgG2a/IgG1 for IgG induced by BLPs plus GEL01 was higher than that of the BLPs alone, suggesting that GEL01 showed adjuvanticity to induce a Th1-polarized immune response. SIgA antibodies may limit MERS-CoV replication at mucosal surfaces. Our data showed that intranasally immunized BLPs could induce mucosal sIgA, especially in the small intestine, confirming that the BLP vaccine could induce strong local mucosal immunity via the intranasal route. To our knowledge, this is the first report that showed successful generation of sIgA in the small intestine among the published MERS-CoV vaccine candidates.

Furthermore, we evaluated splenocytes by ex vivo restimulation, detecting splenocyte proliferation, splenocyte activation and cytokine secretion. The results showed that the BLP vaccine could increase splenocyte proliferation. CD69 is an early marker of activated immune cells [54]. We observed that $\mathrm{B}$ cells, $\mathrm{CD} 4^{+} \mathrm{T}$ cells and $\mathrm{CD} 8^{+} \mathrm{T}$ cells from immunized mouse splenocytes activated more rapidly than those from mock mice once restimulated by antigen. Next, Th1 (IFN- $\gamma$, TNF- $\alpha$ and IL-2) and Th2 (IL-4, IL- 6 and IL-10) in the splenocyte supernatants were detected by ELISA and/or ELISpot. The levels from the BLP vaccine in the presence of the GEL01 adjuvant were higher than those from the BLP vaccine alone. Taken together, GEL01 as a BLP adjuvant can strongly induce systemic and local mucosal immunity. This may be because sodium polyacrylate, the mainly component of the GEL01 adjuvant, promotes the retention of antigens and sustains the release of antigens in the nasal mucosa; in addition, this adjuvant recruits immune cells to the nasal mucosa by the inflammatory response [55].

In summary, we constructed a MERS-CoV bacterium-like particle vaccine displaying the RBD antigen protein in this study. Our results clearly demonstrated that the vaccine can induce strong, specific mucosal immunity in the lungs and intestinal tract and systemic immune responses with the GEL01 adjuvant via the intranasal route. GEL01-adjuvanted MERS-CoV bacterium-like particles are a promising candidate vaccine, and a protective efficacy evaluation of the vaccine in animal models will be considered for future studies.

Author Contributions: X.X., S.Y., Y.Z., and H.C. designed the experiments. E.L., C.L., P.H., Z.W., Y.Z., S.Z., R.M., G.L., and H.J. performed the experiment. F.Y., H.W., N.F., W.J., T.W., W.S., and Y.G. analyzed the data. E.L. and H.C. wrote the manuscript. X.X., S.Y., F.Y., G.L., and Y.B. reviewed the manuscript.

Funding: This work was supported by the National Natural Science Foundation of China (Grant No. 31902306); the National Project for Prevention and Control of Transboundary Animal Diseases (Grant No.2017YFD0501804).

Acknowledgments: In this section you can acknowledge any support given which is not covered by the author contribution or funding sections. This may include administrative and technical support, or donations in kind (e.g., materials used for experiments).

Conflicts of Interest: The authors declare no conflict of interest.

\section{References}

1. Milne-Price, S.; Miazgowicz, K.L.; Munster, V.J. The emergence of the Middle East respiratory syndrome coronavirus. Pathog. Dis. 2014, 71, 119-134. [CrossRef] [PubMed] 
2. Su, S.; Wong, G.; Shi, W.F.; Liu, J.; Lai, A.C.K.; Zhou, J.Y.; Liu, W.J.; Bi, Y.H.; Gao, G.F. Epidemiology, genetic recombination, and pathogenesis of coronaviruses. Trends Microbiol. 2016, 24, 490-502. [CrossRef] [PubMed]

3. Middle East Respiratory Syndrome Coronavirus (Mers-Cov). Available online: https://www.Who.Int/ emergencies/mers-cov/en/ (accessed on 19 July 2019).

4. Ki, M. 2015 mers outbreak in Korea: Hospital-to-hospital transmission. Epidemiol. Health 2015, 37, e2015033. [CrossRef] [PubMed]

5. Su, S.; Wong, G.; Liu, Y.; Gao, G.F.; Li, S.; Bi, Y. Mers in South Korea and China: A potential outbreak threat? Lancet 2015, 385, 2349-2350. [CrossRef]

6. Wang, C.; Zheng, X.X.; Gai, W.W.; Wong, G.; Wang, H.L.; Jin, H.L.; Feng, N.; Zhao, Y.K.; Zhang, W.J.; Li, N.; et al. Novel chimeric virus-like particles vaccine displaying mers-cov receptor-binding domain induce specific humoral and cellular immune response in mice. Antivir. Res. 2017, 140, 55-61. [CrossRef] [PubMed]

7. Du, L.Y.; Kou, Z.H.; Ma, C.Q.; Tao, X.R.; Wang, L.L.; Zhao, G.Y.; Chen, Y.Q.; Yu, F.; Tseng, C.T.K.; Zhou, Y.S.; et al. A truncated receptor-binding domain of mers-cov spike protein potently inhibits mers-cov infection and induces strong neutralizing antibody responses: Implication for developing therapeutics and vaccines. PLoS ONE 2013, 8, e81587. [CrossRef] [PubMed]

8. Zhou, J.; Li, C.; Zhao, G.Y.; Chu, H.; Wang, D.; Yan, H.H.N.; Poon, V.K.M.; Wen, L.; Wong, B.H.Y.; Zhao, X.Y.; et al. Human intestinal tract serves as an alternative infection route for middle east respiratory syndrome coronavirus. Sci. Adv. 2017, 3, eaao4966. [CrossRef] [PubMed]

9. Chi, H.; Zheng, X.; Wang, X.; Wang, C.; Wang, H.; Gai, W.; Perlman, S.; Yang, S.; Zhao, J.; Xia, X. DNA vaccine encoding middle east respiratory syndrome coronavirus s1 protein induces protective immune responses in mice. Vaccine 2017, 35, 2069-2075. [CrossRef]

10. Al-Amri, S.S.; Abbas, A.T.; Siddiq, L.A.; Alghamdi, A.; Sanki, M.A.; Al-Muhanna, M.K.; Alhabbab, R.Y.; Azhar, E.I.; Li, X.; Hashem, A.M. Immunogenicity of candidate mers-cov DNA vaccines based on the spike protein. Sci. Rep. 2017, 7, 44875. [CrossRef]

11. Muthumani, K.; Falzarano, D.; Reuschel, E.L.; Tingey, C.; Flingai, S.; Villarreal, D.O.; Wise, M.; Patel, A.; Izmirly, A.; Aljuaid, A.; et al. A synthetic consensus anti-spike protein DNA vaccine induces protective immunity against Middle East respiratory syndrome coronavirus in nonhuman primates. Sci. Transl. Med. 2015, 7. [CrossRef]

12. Jia, W.X.; Channappanavar, R.; Zhang, C.; Li, M.X.; Zhou, H.X.; Zhang, S.Y.; Zhou, P.P.; Xu, J.Y.; Shan, S.S.; Shi, X.L.; et al. Single intranasal immunization with chimpanzee adenovirus-based vaccine induces sustained and protective immunity against mers-cov infection. Emerg. Microbes Infect. 2019, 8, 760-772. [CrossRef]

13. Haagmans, B.L.; van den Brand, J.M.; Raj, V.S.; Volz, A.; Wohlsein, P.; Smits, S.L.; Schipper, D.; Bestebroer, T.M.; Okba, N.; Fux, R.; et al. An orthopoxvirus-based vaccine reduces virus excretion after mers-cov infection in dromedary camels. Science 2016, 351, 77-81. [CrossRef]

14. Volz, A.; Kupke, A.; Song, F.; Jany, S.; Fux, R.; Shams-Eldin, H.; Schmidt, J.; Becker, C.; Eickmann, M.; Becker, S.; et al. Protective efficacy of recombinant modified vaccinia virus ankara delivering middle east respiratory syndrome coronavirus spike glycoprotein. J. Virol. 2015, 89, 8651-8656. [CrossRef]

15. Guo, X.J.; Deng, Y.; Chen, H.; Lan, J.M.; Wang, W.; Zou, X.H.; Hung, T.; Lu, Z.Z.; Tan, W.J. Systemic and mucosal immunity in mice elicited by a single immunization with human adenovirus type 5 or 41 vector-based vaccines carrying the spike protein of middle east respiratory syndrome coronavirus. Immunology 2015, 145, 476-484. [CrossRef]

16. Liu, R.Q.; Ge, J.Y.; Wang, J.L.; Shao, Y.; Zhang, H.L.; Wang, J.L.; Wen, Z.Y.; Bu, Z.G. Newcastle disease virus-based mers-cov candidate vaccine elicits high-level and lasting neutralizing antibodies in bactrian camels. J. Integr. Agric. 2017, 16, 2264-2273. [CrossRef]

17. Malczyk, A.H.; Kupke, A.; Prufer, S.; Scheuplein, V.A.; Hutzler, S.; Kreuz, D.; Beissert, T.; Bauer, S.; Hubich-Rau, S.; Tondera, C.; et al. A highly immunogenic and protective middle east respiratory syndrome coronavirus vaccine based on a recombinant measles virus vaccine platform. J. Virol. 2015, 89, 11654-11667. [CrossRef]

18. Wirblich, C.; Coleman, C.M.; Kurup, D.; Abraham, T.S.; Bernbaum, J.G.; Jahrling, P.B.; Hensley, L.E.; Johnson, R.F.; Frieman, M.B.; Schnell, M.J. One-health: A safe, efficient, dual-use vaccine for humans and animals against middle east respiratory syndrome coronavirus and rabies virus. J. Virol. 2017, 91. [CrossRef] 
19. Wang, C.; Zheng, X.; Gai, W.; Zhao, Y.; Wang, H.; Wang, H.; Feng, N.; Chi, H.; Qiu, B.; Li, N.; et al. Mers-cov virus-like particles produced in insect cells induce specific humoural and cellular imminity in rhesus macaques. Oncotarget 2017, 8, 12686-12694. [CrossRef]

20. Maslow, J.N. Vaccines for emerging infectious diseases: Lessons from mers coronavirus and zika virus. Hum. Vaccines Immunother. 2017, 13, 2918-2930. [CrossRef]

21. Zhang, N.R.; Jiang, S.B.; Du, L.Y. Current advancements and potential strategies in the development of mers-cov vaccines. Expert Rev. Vaccines 2014, 13, 761-774. [CrossRef]

22. Du, L.Y.; Zhao, G.Y.; Kou, Z.H.; Ma, C.Q.; Sun, S.H.; Poon, V.K.M.; Lu, L.; Wang, L.L.; Debnath, A.K.; Zheng, B.J.; et al. Identification of a receptor-binding domain in the s protein of the novel human coronavirus middle east respiratory syndrome coronavirus as an essential target for vaccine development. J. Virol. 2013, 87, 11963. [CrossRef]

23. Zhang, N.R.; Tang, J.; Lu, L.; Jiang, S.B.; Du, L.Y. Receptor-binding domain-based subunit vaccines against mers-cov. Virus Res. 2015, 202, 151-159. [CrossRef]

24. Lan, J.M.; Deng, Y.; Chen, H.; Lu, G.W.; Wang, W.; Guo, X.J.; Lu, Z.Z.; Gao, G.F.; Tan, W.J. Tailoring subunit vaccine immunity with adjuvant combinations and delivery routes using the middle east respiratory coronavirus (mers-cov) receptor-binding domain as an antigen. PLoS ONE 2014, 9, e112602. [CrossRef]

25. Raj, V.S.; Mou, H.; Smits, S.L.; Dekkers, D.H.; Muller, M.A.; Dijkman, R.; Muth, D.; Demmers, J.A.; Zaki, A.; Fouchier, R.A.; et al. Dipeptidyl peptidase 4 is a functional receptor for the emerging human coronavirus-emc. Nature 2013, 495, 251-254. [CrossRef]

26. Mou, H.; Raj, V.S.; van Kuppeveld, F.J.; Rottier, P.J.; Haagmans, B.L.; Bosch, B.J. The receptor binding domain of the new middle east respiratory syndrome coronavirus maps to a 231-residue region in the spike protein that efficiently elicits neutralizing antibodies. J. Virol. 2013, 87, 9379-9383. [CrossRef]

27. Ma, C.Q.; Wang, L.L.; Tao, X.R.; Zhang, N.R.; Yang, Y.; Tseng, C.T.K.; Li, F.; Zhou, Y.S.; Jiang, S.B.; Du, L.Y. Searching for an ideal vaccine candidate among different mers coronavirus receptor-binding fragments-the importance of immunofocusing in subunit vaccine design. Vaccine 2014, 32, 6170-6176. [CrossRef]

28. Van Roosmalen, M.L.; Kanninga, R.; El Khattabi, M.; Neef, J.; Audouy, S.; Bosma, T.; Kuipers, A.; Post, E.; Steen, A.; Kok, J.; et al. Mucosal vaccine delivery of antigens tightly bound to an adjuvant particle made from food-grade bacteria. Methods 2006, 38, 144-149. [CrossRef]

29. Lee, S.Y.; Choi, J.H.; Xu, Z.H. Microbial cell-surface display. Trends Biotechnol. 2003, 21, 45-52. [CrossRef]

30. Bosma, T.; Kanninga, R.; Neef, J.; Audouy, S.A.L.; van Roosmalen, M.L.; Steen, A.; Buist, G.; Kok, J.; Kuipers, O.P.; Robillard, G.; et al. Novel surface display system for proteins on non-genetically modified Gram-positive bacteria. Appl. Environ. Microb. 2006, 72, 880-889. [CrossRef]

31. Ramasamy, R.; Yasawardena, S.; Zomer, A.; Venema, G.; Kok, J.; Leenhouts, K. Immunogenicity of a malaria parasite antigen displayed by lactococcus lactis in oral immunisations. Vaccine 2006, 24, 3900-3908. [CrossRef]

32. Audouy, S.A.L.; van Selm, S.; van Roosmalen, M.L.; Post, E.; Kanninga, R.; Neef, J.; Estevao, S.; Nieuwenhuis, E.E.S.; Adrian, P.V.; Leenhouts, K.; et al. Development of lactococcal gem-based pneumococcal vaccines. Vaccine 2007, 25, 2497-2506. [CrossRef]

33. Li, P.C.; Qiao, X.W.; Zheng, Q.S.; Hou, J.B. Immunogenicity and immunoprotection of porcine circovirus type 2 (pcv2) cap protein displayed by lactococcus lactis. Vaccine 2016, 34, 696-702. [CrossRef]

34. Buist, G.; Steen, A.; Kok, J.; Kuipers, O.R. Lysm, a widely distributed protein motif for binding to (peptido)glycans. Mol. Microbiol. 2008, 68, 838-847. [CrossRef]

35. Michon, C.; Langella, P.; Eijsink, V.G.H.; Mathiesen, G.; Chatel, J.M. Display of recombinant proteins at the surface of lactic acid bacteria: Strategies and applications. Microb. Cell Fact. 2016, 15, 70. [CrossRef]

36. Steen, A.; Buist, G.; Horsburgh, G.J.; Venema, G.; Kuipers, O.P.; Foster, S.J.; Kok, J. Acma of lactococcus lactis is an n-acetylglucosaminidase with an optimal number of lysm domains for proper functioning. FEBS J. 2005, 272, 2854-2868. [CrossRef]

37. Qiao, X.; Li, P.; Zheng, Q.; Chen, J.; Yu, X.; Hou, L.; Wu, N.; Hou, J. Comparison of the binding activity of lactococcus lactis peptidoglycan protein anchor with different number of motifs. Wei Sheng Wu Xue Bao= Acta Microbiol. Sin. 2015, 55, 193-197.

38. Li, Y.; Wan, Y.H.; Liu, P.P.; Zhao, J.C.; Lu, G.W.; Qi, J.X.; Wang, Q.H.; Lu, X.C.; Wu, Y.; Liu, W.J.; et al. A humanized neutralizing antibody against mers-cov targeting the receptor-binding domain of the spike protein. Cell Res. 2015, 25, 1237-1249. [CrossRef] 
39. Zhang, W.F.; Wang, L.Y.; Liu, Y.; Chen, X.M.; Liu, Q.; Jia, J.L.; Yang, T.Y.; Qiu, S.H.; Ma, G.H. Immune responses to vaccines involving a combined antigen-nanoparticle mixture and nanoparticle-encapsulated antigen formulation. Biomaterials 2014, 35, 6086-6097. [CrossRef]

40. Lindsey, W.B.; Lowdell, M.W.; Marti, G.E.; Abbasi, F.; Zenger, V.; King, K.M.; Lamb, L.S., Jr. Cd69 expression as an index of t-cell function: Assay standardization, validation and use in monitoring immune recovery. Cytotherapy 2007, 9, 123-132. [CrossRef]

41. Assiri, A. Hospital outbreak of middle east respiratory syndrome coronavirus. N. Engl. J. Med. 2013, 369, 886. [CrossRef]

42. Ma, C.Q.; Li, Y.; Wang, L.L.; Zhao, G.Y.; Tao, X.R.; Tseng, C.T.K.; Zhou, Y.S.; Du, L.Y.; Jiang, S.B. Intranasal vaccination with recombinant receptor-binding domain of mers-cov spike protein induces much stronger local mucosal immune responses than subcutaneous immunization: Implication for designing novel mucosal mers vaccines. Vaccine 2014, 32, 2100-2108. [CrossRef]

43. Salminen, S.; von Wright, A.; Morelli, L.; Marteau, P.; Brassart, D.; de Vos, W.M.; Fonden, R.; Saxelin, M.; Collins, K.; Mogensen, G.; et al. Demonstration of safety of probiotics-A review. Int. J. Food Microbiol. 1998, 44, 93-106. [CrossRef]

44. Nganou-Makamdop, K.; van Roosmalen, M.L.; Audouy, S.A.L.; van Gemert, G.J.; Leenhouts, K.; Hermsen, C.C.; Sauerwein, R.W. Bacterium-like particles as multi-epitope delivery platform for plasmodium berghei circumsporozoite protein induce complete protection against malaria in mice. Malar. J. 2012, 11, 50. [CrossRef]

45. Li, B.; Chen, X.R.; Yu, J.F.; Zhang, Y.; Mo, Z.J.; Gu, T.J.; Kong, W.; Wu, Y.G. Protection elicited by nasal immunization with pneumococcal surface protein a (pspa) adjuvanted with bacterium-like particles against streptococcus pneumoniae infection in mice. Microb. Pathog. 2018, 123, 115-119. [CrossRef]

46. Heine, S.J.; Franco-Mahecha, O.L.; Chen, X.T.; Choudhari, S.; Blackwelder, W.C.; van Roosmalen, M.L.; Leenhouts, K.; Picking, W.L.; Pasetti, M.F. Shigella ipab and ipad displayed on 1-lactis bacterium-like particles induce protective immunity in adult and infant mice. Immunol. Cell Biol. 2015, 93, 641-652. [CrossRef]

47. Ramirez, K.; Ditamo, Y.; Rodriguez, L.; Picking, W.L.; van Roosmalen, M.L.; Leenhouts, K.; Pasetti, M.F. Neonatal mucosal immunization with a non-living, non-genetically modified lactococcus lactis vaccine carrier induces systemic and local th1-type immunity and protects against lethal bacterial infection. Mucosal. Immunol. 2010, 3, 159-171. [CrossRef]

48. Rigter, A.; Widjaja, I.; Versantvoort, H.; Coenjaerts, F.E.J.; Van Roosmalen, M.; Leenhouts, K.; Rottier, P.J.M.; Haijema, B.J.; de Haan, C.A.M. A protective and safe intranasal rsv vaccine based on a recombinant prefusion-like form of the $\mathrm{f}$ protein bound to bacterium-like particles. PLoS ONE 2013, 8, e71072. [CrossRef]

49. Bateman, A.; Bycroft, M. The structure of a lysm domain from e-coli membrane-bound lytic murein transglycosylase d (mltd). J. Mol. Biol. 2000, 299, 1113-1119. [CrossRef]

50. Okano, K.; Zhang, Q.; Kimura, S.; Narita, J.; Tanaka, T.; Fukuda, H.; Kondo, A. System using tandem repeats of the ca peptidoglycan-binding domain from lactococcus lactis for display of both $\mathrm{n}$ - and c-terminal fusions on cell surfaces of lactic acid bacteria. Appl. Environ. Microb. 2008, 74, 1117-1123. [CrossRef]

51. Chen, X.Y.; Zaro, J.L.; Shen, W.C. Fusion protein linkers: Property, design and functionality. Adv. Drug Deliv. Rev. 2013, 65, 1357-1369. [CrossRef]

52. Deville, S.; Ben Arous, J.; Bertrand, F.; Borisov, V.; Dupuis, L. Efficacy of intranasal and spray delivery of adjuvanted live vaccine against infectious bronchitis virus in experimentally infected poultry. Procedia Vaccinol. 2012, 6, 85-92. [CrossRef]

53. Nimmerjahn, F.; Ravetch, J.V. Divergent immunoglobulin g subclass activity through selective fc receptor binding. Science 2005, 310, 1510-1512. [CrossRef] [PubMed]

54. Sancho, D.; Gomez, M.; Sanchez-Madrid, F. Cd69 is an immunoregulatory molecule induced following activation. Trends Immunol. 2005, 26, 136-140. [CrossRef] [PubMed]

55. Vialle, R.; Dupuis, L.; Deville, S.; Bertrand, F.; Gaucheron, J.; Aucouturier, J. Microgel particulate adjuvant: Characterisation and mechanisms of action. Procedia Vaccinol. 2010, 2, 12-16. [CrossRef]

(C) 2019 by the authors. Licensee MDPI, Basel, Switzerland. This article is an open access article distributed under the terms and conditions of the Creative Commons Attribution (CC BY) license (http://creativecommons.org/licenses/by/4.0/). 